\title{
Características estruturais e morfológicas de genótipos de Pennisetum sp. sob pastejo no período de seca ${ }^{1}$
}

\section{Márcio Vieira da Cunha ${ }^{2}$, Mércia Virginia Ferreira dos Santos ${ }^{3}$, Mário de Andrade Lira ${ }^{4}$, Alexandre Carneiro Leão de Mello ${ }^{5}$, Rinaldo Luiz Caraciolo Ferreira ${ }^{3}$, Erinaldo Viana de Freitas $^{2}$, José Carlos Nunes ${ }^{6}$}



RESUMO - O experimento foi realizado com o objetivo de estudar características estruturais e morfológicas de cinco genótipos de Pennisetum sp. (CE 08 A.D., Venezuela, HV-241, Elefante B e Hexaplóide) sob pastejo no período de seca na Zona da Mata de Pernambuco. Os genótipos foram manejados sob lotação rotacionada (44 dias de descanso e quatro dias de pastejo) ao longo de dois ciclos de pastejo. Os dados foram analisados em delineamento experimental de blocos ao acaso com parcelas subdivididas (os genótipos representaram as parcelas e os ciclos de pastejo, as subparcelas) e quatro repetições. Houve variação nas características estruturais e morfológicas de genótipos de Pennisetum sp. Os genótipos CE 08 A.D. e Elefante B apresentaram maior densidade de lâmina foliar verde, menor porcentagem de material morto e maior densidade de perfilhos

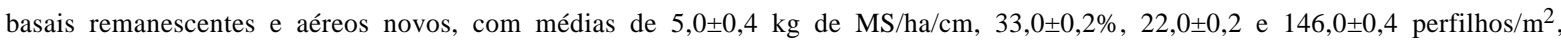
respectivamente. O HV-241 apresentou alta participação de material morto em sua biomassa aérea $(55,6 \pm 0,3 \%)$, o que pode ser atribuído à alta mortalidade de perfilhos $\left(19,0 \pm 0,3\right.$ e $114,0 \pm 0,4$ perfilhos basais e aéreos mortos $/ \mathrm{m}^{2}$, respectivamente). Os genótipos CE 08 A.D. e Elefante B destacaram-se como promissores para utilização sob pastejo no período de seca. O genótipo HV-241, híbrido de capim-elefante com o milheto, foi mais afetado pelos efeitos do estresse hídrico no período seco do ano.

Palavras-chave: altura da pastagem, capim-elefante, frações morfológicas, milheto, perfilhamento

\section{Structural and morphological characteristics of Pennisetum sp. genotypes under grazing during the dry period}

\begin{abstract}
The experiment was carried out to study structural and morphologic characteristics of five Pennisetum sp. genotypes (CE 08 A.D., Venezuela, HV-241, Elephant B and Hexaplóide) under grazing during the dry period in Pernambuco Forest Zone. Genotypes were managed under rotational stocking (44 days of resting and four days of grazing period). The experimental design was randomized blocks in a split plot arrangement, and four replications. The genotypes represented the plots, and grazing cycles, the subplots. There was variation in the structural and morphologic characteristics of the Pennisetum sp. genotypes. The CE 08 A.D. and Elephant B presented high density of green leaf blade, low percentage of dead material and high density of remaining basal tillers and new aerial tillers, with averages of $5.0 \pm 0.4 \mathrm{~kg} \mathrm{DM} / \mathrm{ha} / \mathrm{cm} ; 33 \pm 0.2 \% ; 22 \pm 0.2$ and $146 \pm 0.4$ tillers $/ \mathrm{m}^{2}$, respectively. The HV-241 presented high participation of dead material in its aerial biomass $(55.6 \pm 0.3 \%)$ due to high tiller mortality $\left(19 \pm 0.3\right.$ and $114 \pm 0.4$ basal and aerial dead tillers $/ \mathrm{m}^{2}$, respectively). The genotypes CE 08 A.D. and Elephant B had been distinguished as promising to be used under grazing in the dry period. The genotype HV-241, elephantgrass hybrid with pearl millet, was more affected by water stress during the dry period of the year.
\end{abstract}

Key Words: elephantgrass, millet, morphological fractions, pasture height, tillering

\section{Introdução}

O capim-elefante (Pennisetum purpureum Schum.) tem se destacado entre as forrageiras mais utilizadas nos sistemas intensivos de produção animal em pastagem, em decorrência do seu potencial produtivo e de sua qualidade quando devidamente manejado (Cóser et al., 2001).

Muitos esforços têm sido realizados com vistas à utilização dessa forrageira para formação de pastagens. Entre esses esforços, destaca-se a seleção de materiais adaptados ao sistema de lotação rotacionada. A hibridação 
interespecífica do capim-elefante com o milheto é um método usado no melhoramento do capim-elefante visando ao aproveitamento da rusticidade e qualidade do milheto.

A produção do capim-elefante se concentra no período chuvoso do ano, quando as condições ambientais são favoráveis para seu pleno crescimento. Todavia, esta espécie, assim como a maioria das gramíneas tropicais, possui marcante estacionalidade na produção de forragem (Lopes et al., 2005). Apesar de estabelecido que o crescimento do capim-elefante e de seus híbridos com milheto é afetado pelo estresse hídrico (Barreto et al., 2001), são escassos os trabalhos que caracterizam a estrutura e morfologia da pastagem associadas ao efeito do pastejo em genótipos de Pennisetum sp. no período da seca.

Em ambiente de pasto, as características inerentes à gramínea, o manejo de pastejo e a época do ano são os principais fatores que determinam a arquitetura da planta (Bullock et al., 2001). Assim, características como altura, densidade de lâmina foliar, perfilhamento e proporções de lâmina foliar, colmo e material morto, que, por sua vez, compõem a arquitetura da planta, influenciam o consumo e o desempenho animal na pastagem (Newman et al., 2003).

Objetivou-se neste estudo estudar as características estruturais e morfológicas de genótipos de Pennisetum $\mathrm{sp}$. sob pastejo no período da seca na Zona da Mata de Pernambuco.

\section{Material e Métodos}

O experimento foi realizado na Estação Experimental da Empresa Pernambucana de Pesquisa Agropecuária (IPA), no município de Itambé, Zona da Mata Seca de Pernambuco. O município situa-se nas coordenadas geográficas $07^{\circ} 25^{\prime} 00^{\prime \prime} \mathrm{Se} 35^{\circ} 06^{\prime} 00^{\prime \prime} \mathrm{WGr}$, a $190 \mathrm{~m}$ de altitude, com precipitação média anual de $1.356 \mathrm{~mm}$ (SUDENE, 1990) e temperatura média anual de $25^{\circ} \mathrm{C}$ (Encarnação, 1980). As avaliações experimentais foram realizadas no período de seca (dezembro de 2004 a abril de 2005), quando a precipitação média foi de $170 \mathrm{~mm}$.

Foram avaliados cinco genótipos de Pennisetum sp.: três de capim-elefante (CE 08 A.D., Venezuela, Elefante B) e dois híbridos do capim-elefante com milheto (HV-241 e Hexaplóide). Os genótipos foram selecionados das Fases I (Mello et al., 2002) e II (Freitas et al., 2004) do Programa de Melhoramento Genético do capim-elefante, realizado pelo IPA/UFRPE.

O experimento foi realizado em uma área de 5 ha, dividida em 12 piquetes. Os piquetes foram subdivididos em cinco áreas de aproximadamente $833 \mathrm{~m}^{2}$, cada uma ocupada por um genótipo. A pastagem foi estabelecida no início do segundo semestre de 2003, após aragem, gradagem e correção do solo com 1,0 t de calcário dolomítico/ha, conforme resultados da análise do solo $(\mathrm{pH}$ em água $=5,3$; $\mathrm{P}=3,83 \mathrm{ppm} ; \mathrm{K}^{+}=0,3 ; \mathrm{Ca}^{++}=3,1 ; \mathrm{Mg}^{++}=1,5 ; \mathrm{e} \mathrm{Al}^{+++}=$ $0,3 \mathrm{cmol}_{\mathrm{c}} / \mathrm{dm}^{3}$ ). No plantio, foram utilizadas frações de colmo e espaçamento de $1 \mathrm{~m}$ entre linhas.

Antes do início do período experimental, as pastagens apresentavam aproximadamente 100 dias de crescimento e altura média de $2,5 \mathrm{~m}$. Visando à quebra da dominância apical e à uniformização das pastagens, os genótipos foram submetidos a pastejo durante 15 dias. Depois de aproximadamente dois meses, um ciclo de pastejo de 48 dias ( 44 dias de descanso e quatro dias de ocupação) antecedeu o início do experimento.

No período experimental, a pastagem foi manejada com ciclo de pastejo de 48 dias (44 dias de descanso e quatro dias de ocupação) utilizando-se vacas mestiças holandês x zebu (470 kg de PV), em lotação de dois animais/ha para cada genótipo. Diariamente, os animais receberam suplementação (30 kg/animal da mistura cana-de-açúcar enriquecida com $1 \%$ de uréia + sulfato de amônia) no cocho, após a única ordenha pela manhã, e retornaram à pastagem às $14 \mathrm{~h}$.

As avaliações, realizadas alternadamente a cada dois piquetes, durante dois ciclos de pastejo, ocorreram antes de os animais entrarem no piquete (pré-pastejo) e depois de saírem do mesmo piquete (pós-pastejo), em dois piquetes consecutivos. Avaliaram-se a altura média da pastagem, as densidades de lâminas foliares total, verde e seca, as frações morfológicas da pastagem (porcentagens de lâmina foliar verde, colmo e material morto) e o perfilhamento, cuja avaliação foi feita apenas no período pré-pastejo.

A altura média da pastagem foi determinada utilizando-se uma régua graduada, em centímetros, em três pontos amostrais/genótipo. As alturas representaram a variação na massa de lâmina foliar total (massas de lâmina foliar total maior, menor e média) pré e pós-pastejo. Em cada ponto, a altura correspondeu ao comprimento médio do nível do solo à curvatura da última folha completamente expandida, no pré-pastejo, e do nível do solo à extremidade das folhas pastejadas, no pós-pastejo, como descrito por Quadros et al. (2002).

As densidades de lâminas foliares total (lâmina foliar verde e seca), verde e seca $(\mathrm{kg}$ de $\mathrm{MS} / \mathrm{ha} / \mathrm{cm})$ foram obtidas segundo Stobbs (1973), por meio da relação entre as massas de lâminas foliares total, verde e seca e a altura média da pastagem pré e pós-pastejo. As massas de lâmina foliar total (lâminas foliares verde e seca) pré e pós-pastejo foram estimadas conforme a técnica de dupla amostragem (Wilm 
et al., 1944). A colheita manual das lâminas foliares foi feita nos três pontos amostrais de mensuração da altura, considerando em cada ponto uma área correspondente a $1 \mathrm{~m}^{2}$, delimitada por um quadrado de PVC. O material colhido foi separado em lâminas verdes e secas e, após a pesagem de cada componente, foi retirada uma amostra para determinação da MS em estufa a $55^{\circ} \mathrm{C}$. Em seguida, conforme a variação estipulada na massa de lâmina foliar, foram determinados visualmente no piquete 30 pontos amostrais de $1 \mathrm{~m}^{2}$. A massa de lâmina foliar total no piquete correspondeu à freqüência de cada ponto amostral multiplicada pelo seu respectivo peso. A massa de lâmina foliar total ( $\mathrm{kg}$ de MS/ha) foi estimada com base na MS a partir da porcentagem de lâminas foliares verdes e secas.

Após a colheita manual das lâminas foliares nos pontos amostrais pré e pós-pastejo, os colmos foram cortados rente ao solo e classificados em vivos ou mortos. Em seguida, depois de pesadas, as amostras de cada componente foram mantidas em estufa a $55^{\circ} \mathrm{C}$ até peso constante. Depois de separadas lâminas verdes e secas para estimativa da massa de lâmina foliar total, as frações morfológicas dos genótipos de Pennisetum sp. foram expressas em porcentagem de lâmina foliar verde, colmo (colmo e bainha foliar) e material morto (lâmina foliar seca e colmo morto) na biomassa aérea pré e pós-pastejo, calculada com base na MS de cada componente. A biomassa aérea correspondeu ao somatório de massa de lâmina foliar total e colmos vivos e mortos.

A densidade de perfilhos (perfilhos $/ \mathrm{m}^{2}$ ) aéreos e basais foi estimada pela contagem das diferentes classes desses perfilhos na biomassa aérea pré-pastejo dos genótipos: perfilhos remanescentes (perfilhos que sobreviveram aos pastejos anteriores, com colmo bastante lignificado), novos (perfilhos tenros) e mortos (perfilhos cujos colmos e lâmina foliares apresentavam-se completamente senescidos). A contagem foi realizada no ponto amostral que representou a massa de lâmina foliar total média.

Os dados foram analisados em delineamento experimental em blocos ao acaso com parcelas subdivididas e quatro repetições (blocos). Os cinco genótipos de Pennisetum sp. corresponderam às parcelas e os dois ciclos de pastejo, às subparcelas. Os piquetes representaram os blocos experimentais em virtude da heterogeneidade do terreno (inclinação e características químicas do solo).

As análises estatísticas foram realizadas por meio do pacote estatístico SAS (Statistical Analysis System) (SAS, 1999). A normalidade dos dados foi testada pelo procedimento UNIVARIATE do SAS e a homogeneidade da variância, pelo teste de Bartlett. Os dados de altura da pastagem pré e pós-pastejo e das densidades de lâminas foliares total, verde e seca pré-pastejo foram transformados em $\sqrt{x}$. Para as densidades de lâminas foliares total e verde e para a porcentagem de material morto pós-pastejo, além daquelas relacionadas ao perfilhamento, os dados foram transformados em $\sqrt{x+1}$. Os dados da porcentagem de colmo pós-pastejo sofreram transformação logarítmica. Para realização da análise de variância, utilizou-se o procedimento GLM (General Linear Models) do SAS. As médias entre genótipos foram comparadas pelo teste Tukey, a 5 ou $10 \%$ de significância, conforme a significância do teste $\mathrm{F}$ na análise de variância. As médias entre ciclos de pastejo foram comparadas pelo teste $\mathrm{F}$ a 5 ou $10 \%$ de significância.

\section{Resultados e Discussão}

Não houve efeito da interação genótipo $\times$ ciclo de pastejo sobre a altura média da pastagem pré e pós-pastejo ( $\mathrm{P}=0,1443$ e 0,4588 , respectivamente). No pré-pastejo, a altura média da pastagem não diferiu $(\mathrm{P}=0,3565)$ entre os genótipos de Pennisetum sp. e apresentou média de $154 \pm 0,1 \mathrm{~cm}$. No pós-pastejo, no entanto, os genótipos de Pennisetum sp. diferiram $(\mathrm{P}=0,0725)$ quanto à altura média da pastagem. Os genótipos CE 08 A.D., Elefante B e Hexaplóide apresentaram altura superior à dos genótipos Venezuela e HV-241 (Tabela 1).

Independentemente do genótipo, o pastejo reduziu a altura média da pastagem. A altura média pré e pós-pastejo diminuiu ( $\mathrm{P}<0,0001$ e $\mathrm{P}=0,0110$, respectivamente) do primeiro para o segundo ciclo de pastejo (Tabela 1), o que está associado à redução na altura média da pastagem após o período de ocupação do piquete, que, no primeiro ciclo de pastejo, foi de $13 \%$ e, no segundo ciclo, de $8 \%$ da altura prépastejo. Além disso, a redução na altura promovida pelo pastejo não foi compensada pelo crescimento durante o período de descanso da pastagem, o que representou incremento de apenas $2 \%$ na altura. O baixo crescimento dos genótipos pode ser explicado pelas limitações ambientais na época seca, notadamente a baixa pluviosidade.

Os genótipos apresentaram diferentes densidades de lâmina foliar total e verde pré-pastejo $(\mathrm{P}=0,0265$ e $\mathrm{P}<0,0001$, respectivamente). Quanto à densidade de lâmina foliar total, o CE 08 A.D. e Elefante B foram superiores ao HV-241, enquanto o Venezuela e Hexaplóide não diferiram dos demais (Tabela 2).

O genótipo CE 08 A.D. foi superior aos demais quanto à densidade de lâmina foliar verde, mas não diferiu do Elefante B, cuja densidade não diferiu daquela do Venezuela e Hexaplóide. A menor densidade de lâmina foliar verde foi 
Tabela 1 - Altura média da pastagem $(\mathrm{cm})$ de genótipos de Pennisetum sp. nos períodos pré e pós-pastejo

Table 1 - Pre-grazing and post-grazing average pasture height (cm) of Pennisetum sp. genotypes

\begin{tabular}{cc}
\hline $\begin{array}{c}\text { Pré-pastejo } \\
\text { Pre-grazing }\end{array}$ & $\begin{array}{c}\text { Pós-pastejo }^{1} \\
\text { Post-grazing }^{2}\end{array}$ \\
\hline
\end{tabular}

Genótipo (Genotype)

$\begin{array}{lll}\text { CE 08 A.D. } & 158 \mathrm{a} & 142 \mathrm{a} \\ \text { Venezuela } & 156 \mathrm{a} & 131 \mathrm{~b} \\ \text { HV-241 } & 149 \mathrm{a} & 132 \mathrm{~b} \\ \text { Elefante B } & 158 \mathrm{a} & 143 \mathrm{a} \\ \text { Hexaplóide } & 150 \mathrm{a} & 142 \mathrm{a}\end{array}$

Ciclos de pastejo (Grazing cycle)

$\begin{array}{lrr}\text { Ciclo } 1 \text { (Cycle 1) } & 164 \mathrm{~A} & 142 \mathrm{~A} \\ \text { Ciclo 2 (Cycle 2) } & 145 \mathrm{~B} & 134 \mathrm{~B} \\ \text { Média (Mean) } & 154 & 138 \\ \mathrm{CV}_{\text {genótipo }} \%\left(C V_{\text {genotype, }} \%\right) & 4 & 5 \\ \mathrm{CV}_{\text {ciclo de pastejo, \% }}\left(\mathrm{CV}_{\text {grazing cycle, }} \%\right) & 4 & 4\end{array}$

Em genótipos, médias seguidas de letras minúsculas diferentes na coluna diferem $(P<0,10)$ pelo teste Tukey.

Em ciclos de pastejo, médias seguidas de letras maiúsculas diferentes na coluna diferem $(\mathrm{P}<0,05)$ pelo teste $\mathrm{F}$.

Os dados foram submetidos à transformação $\sqrt{x}$.

Means followed by different lower case letters in the column, in genotypes, are different $(P<0.10)$ by Tukey test.

Means followed by different upper case letters in the column, in grazing cycles, are different $(P<0.05)$ by F test.

The data was transformed to $\sqrt{x}$.

obtida com o HV-241. A densidade de lâmina foliar seca não diferiu ( $\mathrm{P}=0,9560)$ entre os genótipos de Pennisetum sp., com média de 3,9 $\pm 0,1 \mathrm{~kg}$ de MS/ha/cm (Tabela 2).

De acordo com Black \& Kenney (1984), o consumo está relacionado à densidade de forragem quando a altura das pastagens é similar. No pré-pastejo, os genótipos de Pennisetum sp. apresentaram alturas médias similares, entretanto, com diferentes densidades de lâmina foliar total e verde, o que pode ter influenciado o padrão de desfolha e contribuído para as diferentes alturas médias da pastagem pós-pastejo nos genótipos.

A menor altura média da pastagem pós-pastejo no Venezuela e no HV-241 pode ter sido ocasionada pela maior intensidade de pastejo nesses genótipos, cuja lotação animal foi a mesma utilizada nos demais, porém com baixas densidades de lâmina foliar total e verde. A densidade de forragem e a altura da pastagem são características estruturais que afetam a facilidade de apreensão e o tamanho do bocado pelo animal, principal atributo a influenciar o consumo diário de MS em pastagens tropicais (Hodgson et al., 1994).

As densidades de lâminas foliares total, verde e seca pré-pastejo diferiram ( $\mathrm{P}=0,1000 ; 0,0003$ e 0,0003, respectivamente) entre os ciclos de pastejo. As densidades de lâmina foliar total e seca, no entanto, reduziram do primeiro para o segundo ciclo, denotando aumento na densidade de lâmina foliar verde (Tabela 2). Apesar de as lâminas foliares verdes terem sido intensamente removidas pelo pastejo, o
Tabela 2 - Densidade ( $\mathrm{kg}$ de MS/ha/cm) de lâminas foliares total, verde e seca em genótipos de Pennisetum sp. no período pré-pastejo

Table 2 - Pre-grazing total, green and dry leaf blade bulk density (kg DM/ $\mathrm{ha} / \mathrm{cm}$ ) in Pennisetum sp. genotypes

\begin{tabular}{|c|c|c|c|}
\hline & $\begin{array}{l}\text { Lâmina } \\
\text { foliar total }{ }^{1} \\
\text { Total leaf blade }\end{array}$ & $\begin{array}{c}\text { Lâmina } \\
\text { foliar verde } \\
\text { Green leaf blade }\end{array}$ & $\begin{array}{c}\text { Lâmina } \\
\text { foliar seca } \\
\text { Dry leaf blade }\end{array}$ \\
\hline \multicolumn{4}{|c|}{ Genótipo (Genotype) } \\
\hline CE 08 A.D. & $8,7 \mathrm{a}$ & $5,0 \mathrm{a}$ & $3,7 \mathrm{a}$ \\
\hline Venezuela & $7,1 \mathrm{ab}$ & $3,0 \mathrm{~b}$ & $4,1 \mathrm{a}$ \\
\hline HV-241 & $5,6 b$ & $1,3 \mathrm{c}$ & $4,3 \mathrm{a}$ \\
\hline Elefante B & $8,7 \mathrm{a}$ & $4,5 \mathrm{ab}$ & $4,2 \mathrm{a}$ \\
\hline Hexaplóide & $6,3 \mathrm{ab}$ & $3,1 b$ & $3,2 \mathrm{a}$ \\
\hline
\end{tabular}

Ciclos de pastejo (Grazing cycle)

$\begin{array}{lrrr}\text { Ciclo 1 (Cycle 1) } & 7,7 \mathrm{~A} & 2,7 \mathrm{~B} & 4,9 \mathrm{~A} \\ \text { Ciclo 2 (Cycle 2) } & 7,0 \mathrm{~B} & 3,9 \mathrm{~A} & 2,9 \mathrm{~B} \\ \text { Média (Mean) } & 7,3 & 3,5 & 3,9 \\ \mathrm{CV} & 18 \text { genótipo, \% } & 18 & 33 \\ C V_{\text {genotype, } \%} & & & 31 \\ \mathrm{CV} \text { ciclo de pastejo, } \% & 15 & 16 & \\ C V_{\text {grazing cycle, }} \% & & & \end{array}$

Médias seguidas de letras minúsculas diferentes na coluna, em genótipos, diferem $(P<0,05)$ pelo teste de Tukey.

Médias seguidas de letras maiúsculas diferentes na coluna, em ciclos de pastejo, diferem $(P<0,10$, na segunda coluna, e $P<0,05$, na terceira e quarta coluna) pelo teste $\mathrm{F}$.

Os dados foram submetidos a transformação $\sqrt{x}$.

Means followed by different lower case letters in the column, in genotypes, are different $(P<0.10)$ by Tukey test.

Means followed by different upper case letters in the column, in grazing cycle, are different $(P<0.10$, in the second column, and $P<0.05$, in the third and forth column) by F test.

The data was transformed to $\sqrt{x}$.

que representou $97 \%$ da densidade de lâmina foliar verde pré-pastejo, considerando as médias de densidade de lâmina foliar verde pré e pós-pastejo, provavelmente a remoção das lâminas mais velhas e secas pelo pastejo permitiu maior entrada de luz no dossel, estimulando a produção de novas folhas. Assim, a maior densidade de lâminas foliares verdes no segundo ciclo de pastejo resultou do aumento de folhas verdes e da diminuição na altura dos genótipos de Pennisetum sp. entre os ciclos.

A interação genótipo $\times$ ciclo de pastejo não influenciou significativamente $(\mathrm{P}=0,1636 ; 0,1979$ e 0,9560 , respectivamente) as densidades de lâminas foliares total, verde e seca pré-pastejo, mas afetaram $(\mathrm{P}=0,0764 ; 0,0025$ e 0,0812, respectivamente) essas características no período póspastejo (Figura 1). As densidades de lâminas foliares total e seca pós-pastejo reduziram do primeiro para o segundo ciclo de pastejo apenas no Venezuela e Elefante B (Figuras 1A e 1C). A densidade de lâminas foliares verdes póspastejo sofreu tendência inversa, apresentando aumento de um ciclo a outro, porém apenas no Elefante B (Figura 1B).

Os genótipos de Pennisetum sp. diferiram quanto à porcentagens de lâmina foliar verde, colmo e material morto 


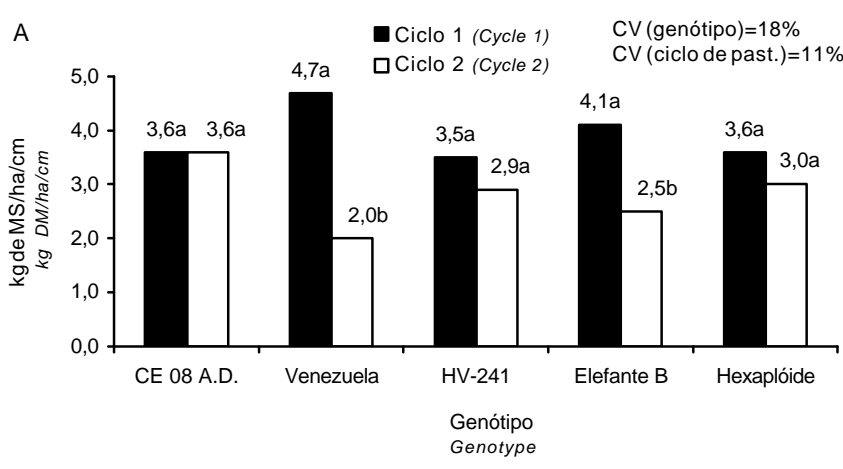

B

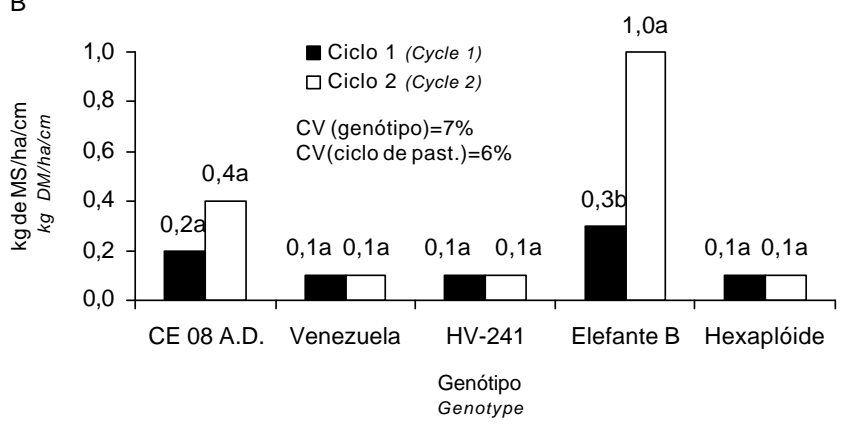

C

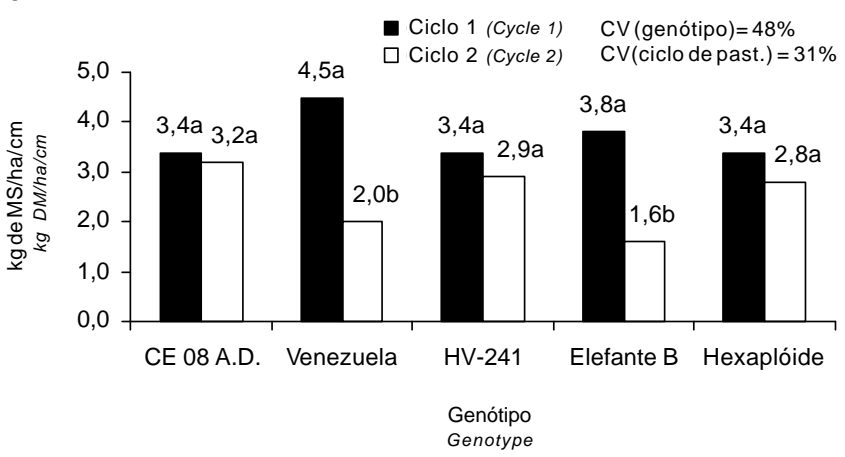

Figura 1 - Densidades de lâminas foliares total (A), verde (B) e seca (C) pós-pastejo em genótipos de Pennisetum $\mathrm{sp}$.

Figure 1 - Total (A), green (B), and dry (C) post-grazing bulk density in Pennisetum sp. genotypes.

Médias com letras diferentes, dentro dos genótipos, diferem $(P<0,10$, em A e C; $P<0,05$, em B) pelo teste $F$.

Means in genotypes, with different letters are different $(P<0.10$, in $A$ and $C$; $P<0.05$, in $B)$ by $F$ test.

Em A e B: dados foram submetidos a transformação $\sqrt{x+1}$.

In $A$ and $B$, data was transformed to $\sqrt{x+1}$.

na biomassa aérea pré-pastejo ( $\mathrm{P}=0,0006 ; 0,0031$ e 0,0019 , respectivamente) e quanto às porcentagens de colmo $\mathrm{e}$ material morto na biomassa aérea pós-pastejo $(\mathrm{P}=0,0124 \mathrm{e}$ 0,0178 , respectivamente).

Os resultados obtidos no pós-pastejo foram semelhantes aos do pré-pastejo. Desse modo, a porcentagem de colmo no genótipo Venezuela foi maior que no HV-241, cuja porcentagem de material morto foi maior que nos demais genótipos, à exceção do Hexaplóide (Figura 2B).

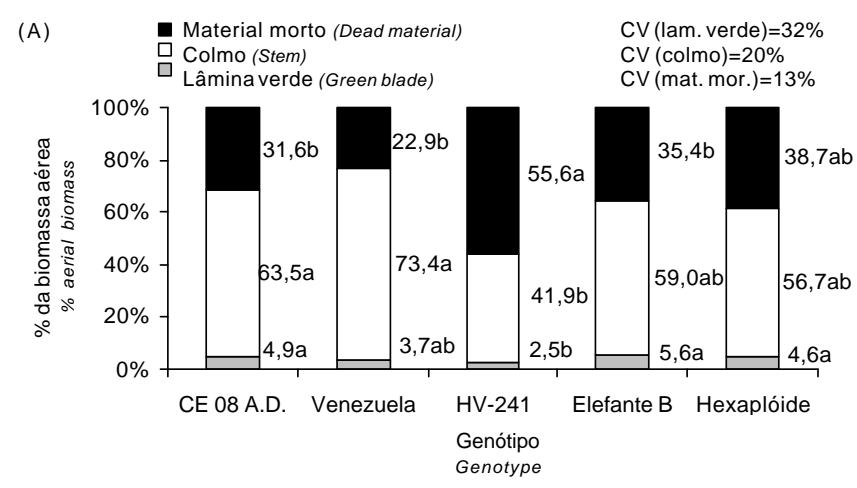

(B)

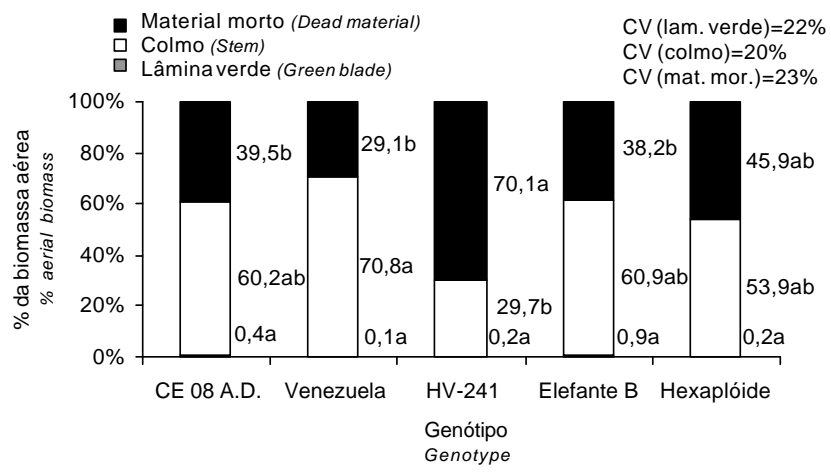

Figura 2 - Frações morfológicas de genótipos de Pennisetum sp. nos períodos pré (A) e pós-pastejo (B)

Figure 2 - Pre-grazing $(A)$ and post-grazing $(B)$ morphological fractions of Pennisetum sp. genotypes.

Médias entre genótipos seguidas de letras diferentes comparam as frações morfológicas e diferem $(\mathrm{P}<0,05)$ pelo teste Tukey. Means between genotypes, followed by different letters, compare morphological fractions and are different $(P<0.05)$ by Tukey test.

Os dados referentes a material morto pós-pastejo foram submetidos à transformação logx.

The post-grazing dead material was transformed to logx.

No pré-pastejo, os genótipos CE 08 A.D., Elefante B e Hexaplóide apresentaram maior porcentagem de lâmina foliar verde em comparação ao HV-241, cuja porcentagem de colmo foi menor que no CE 08 A.D. e no Venezuela. Quando comparado aos demais, exceto ao Hexaplóide, o HV-241 apresentou a maior porcentagem de material morto (Figura 2A).

O pastejo adotado no manejo da pastagem antes do início do experimento não foi eficiente em remover a grande quantidade de biomassa aérea acumulada durante os meses de maior pluviosidade no ano de 2004, quando os genótipos de Pennisetum sp. cresceram livremente. Assim, a produção líquida das pastagens foi comprometida pelo alongamento dos colmos e pelo acúmulo de material morto. Essa diminuição da produção líquida no período de livre crescimento da pastagem, associada aos efeitos da seca, pode ter ocasionado a baixa participação de lâmina foliar verde na biomassa aérea dos genótipos de Pennisetum sp. 
A morfologia da pastagem afeta a facilidade de apreensão da forragem pelos animais (Burns et al., 1992). Desse modo, maior porcentagem de colmo e de material morto na biomassa aérea das pastagens representa barreiras que restringem a massa do bocado (Baumont et al., 2000) e a seletividade animal, maximizando as diferenças no consumo entre genótipos de plantas (Cherney et al., 1990).

De modo geral, a participação de colmos e material morto na biomassa aérea pós-pastejo dos genótipos de Pennisetum sp. aumentou, indicando seletividade dos animais pela fração verde da pastagem (Figura 3B). De acordo com Gomide et al. (2001), a seletividade bovina prioriza as folhas verdes, mais novas e de maior valor nutritivo, em detrimento das mais velhas e secas e do colmo. Nutricionalmente, as folhas são a fração mais importante da pastagem e, portanto, características da pastagem relacionadas a esta fração representam os principais fatores que influenciam o consumo e a produção animal sob pastejo (Burns \& Sollenberger, 2002).

A porcentagem de lâmina foliar verde pré-pastejo aumentou $(\mathrm{P}=0,0055)$ do primeiro para o segundo ciclo de pastejo, como resultado da redução $(\mathrm{P}=0,0760)$ na porcentagem de colmo entre os ciclos. Isso ocorreu porque a porcentagem de material morto na biomassa aérea dos genótipos de Pennisetum sp. permaneceu constante e não diferiu ( $\mathrm{P}=0,1308)$ entre os ciclos de pastejo (Figura 3$)$. A porcentagem de colmo $(55,9 \pm 0,1)$ e material morto $(43,7 \pm 0,2)$ na biomassa aérea pós-pastejo não diferiu entre os ciclos de pastejo $(\mathrm{P}=0,6114$ e 0,9050 , respectivamente $)$.

É provável que o pastejo tenha promovido alterações morfológicas na pastagem. Desse modo, a quebra dos colmos pelo pastejo pode ter permitido maior entrada de luz no dossel forrageiro e, assim como em relação à densidade de lâmina foliar verde pré-pastejo, ter favorecido o aumento de folhas verdes do primeiro para o segundo ciclo. De acordo com Fagundes et al. (2001), a interceptação de luz é regulada por uma série de fatores, entre eles, a composição morfológica da pastagem, o hábito de crescimento da planta e a estrutura da pastagem. Esse conjunto de características determina o grau de atenuação da luz no dossel forrageiro.

Houve efeito significativo $(\mathrm{P}=0,0008)$ da interação genótipo $\times$ ciclo de pastejo sobre a porcentagem de lâmina foliar verde pós-pastejo. Assim, apenas no Elefante B, a porcentagem de lâmina foliar verde aumentou do primeiro para o segundo ciclo de pastejo (Figura 4).

No pré-pastejo, as frações morfológicas das pastagens não foram influenciadas $(\mathrm{P}=0,3071 ; 0,2878$ e 0,233 para porcentagens de folhas verdes, colmo e material morto, respectivamente) pela interação genótipo $\times$ ciclo de pastejo. Também não houve efeito significativo $(\mathrm{P}=0,4146$ e 0,1240 ,

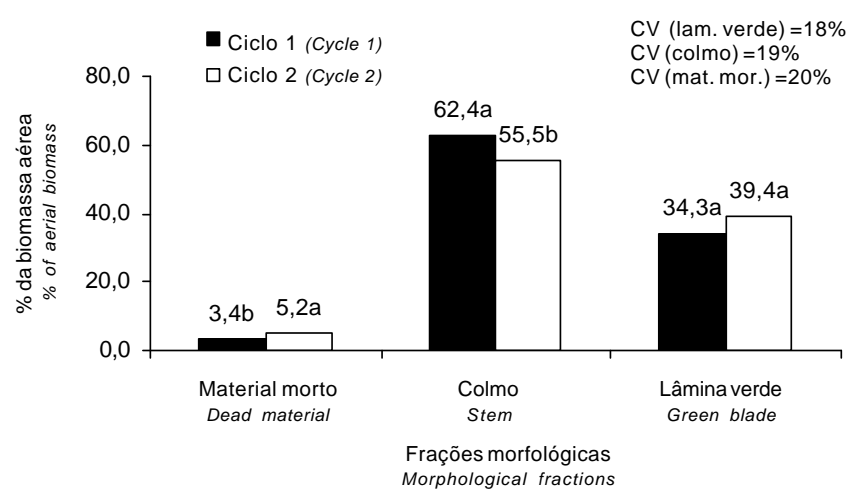

Figura 3 - Frações morfológicas da pastagem de Pennisetum sp. no pré-pastejo em dois ciclos de pastejo.

Figure 3 - Pre-grazing morphological fractions of the pasture in two grazing cycles.

Médias seguidas de letras minúsculas diferentes dentro de cada fração diferem $(P<0,05)$ pelo teste $F$.

Means followed by different letters, in genotypes are different $(P<0.05)$ by F test.

Os dados referentes a material morto pós-pastejo foram submetidos à transformação logx.

The post-grazing dead material was transformed to logx.

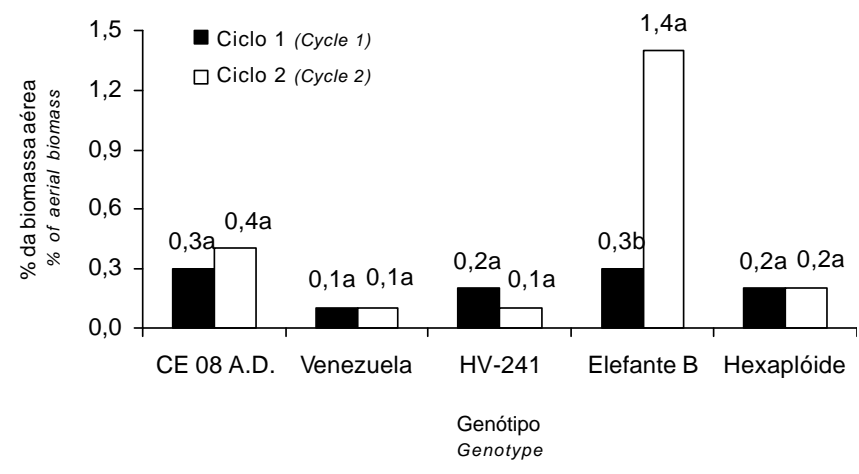

Figura 4 - Porcentagem de lâmina foliar verde em genótipos de Pennisetum sp. no pós-pastejo.

Figure 4 - Percentage of post-grazing green leaf blade in Pennisetum sp. genotypes.

Médias seguidas de letras diferentes, dentro de genótipos, diferem $(P<0,05)$ pelo teste de Tukey.

Means followed by different letters, in genotypes, are different $(P<0.05)$ by Tukey test.

respectivamente) da interação genótipo $\times$ ciclo de pastejo sobre as porcentagens de colmo e material morto pós-pastejo.

No período pré-pastejo, os genótipos de Pennisetum sp. apresentaram diferentes $(\mathrm{P}=0,0036$ e 0,0005 , respectivamente) densidades de perfilhos basais e aéreos. O genótipo Elefante $B$ apresentou maior a densidade de perfilhos basais. A densidade de perfilhos aéreos nesse genótipo foi superior à obtida no Hexaplóide e Venezuela, cuja densidade de perfilhos aéreos foi a menor (Figura 5). 




Figura 5 - Densidade de perfilhos em genótipos de Pennisetum sp. no pré-pastejo.

Figure 5 - Tiller density in Pennisetum sp. genotypes.

Médias seguidas de letras diferentes, entre genótipos, diferem $(P<0,05)$ pelo teste Tukey.

Means followed by different letters among genotypes are different $(P<0.05)$ by Tukey test.

Os dados foram submetidos à transformação $\sqrt{x+1}$.

The data was transformed to $\sqrt{x+1}$.

A densidade de perfilhos basais e aéreos não foi influenciada ( $\mathrm{P}=0,9400$ e 0,5887$)$ pelo ciclo de pastejo nem pela interação genótipo $\times$ ciclo de pastejo $(P=0,9278$ e 0,9488 , respectivamente). Os genótipos de Pennisetum sp. apresentaram, no entanto, diferentes densidades de perfilhos basais remanescentes $(\mathrm{P}=0,0036)$ e mortos $(\mathrm{P}<0,0001)$.

Assim, a densidade de perfilhos basais remanescentes no genótipo Elefante B foi maior que no Venezuela, no qual a densidade de perfilhos basais mortos foi a menor (Figura 6), o que pode estar associado à baixa densidade de perfilhos basais neste genótipo (Figura 5).

A densidade de perfilhos basais novos não diferiu $(\mathrm{P}=0,1640)$ entre os genótipos de Pennisetum sp., com média de $3,1 \pm 0,1$ perfilhos $/ \mathrm{m}^{2}$ (Figura $6 \mathrm{~A}$ ), indicando que, durante o período de seca, o perfilhamento basal é limitado, provavelmente em decorrência da baixa umidade no solo e da alocação de recursos para perfilhos aéreos, sistema radicular ou ambos.

Quanto às classes de perfilhos aéreos (Figura 6B), os genótipos de Pennisetum sp. apresentaram diferentes densidades de perfilhos aéreos remanescentes $(P=0,0157)$, novos $(\mathrm{P}<0,0001)$ e mortos $(\mathrm{P}<0,0001)$. A densidade de perfilhos aéreos remanescentes no genótipo CE 08 A.D. foi maior que no Venezuela, no qual a densidade de perfilhos aéreos foi inferior à de todos os genótipos, exceto o Hexaplóide. No elefante B, a densidade de perfilhos aéreos novos foi maior que no HV-241, Venezuela e Hexaplóide. Entre os genótipos avaliados, o Venezuela apresentou a menor densidade perfilhos aéreos mortos.
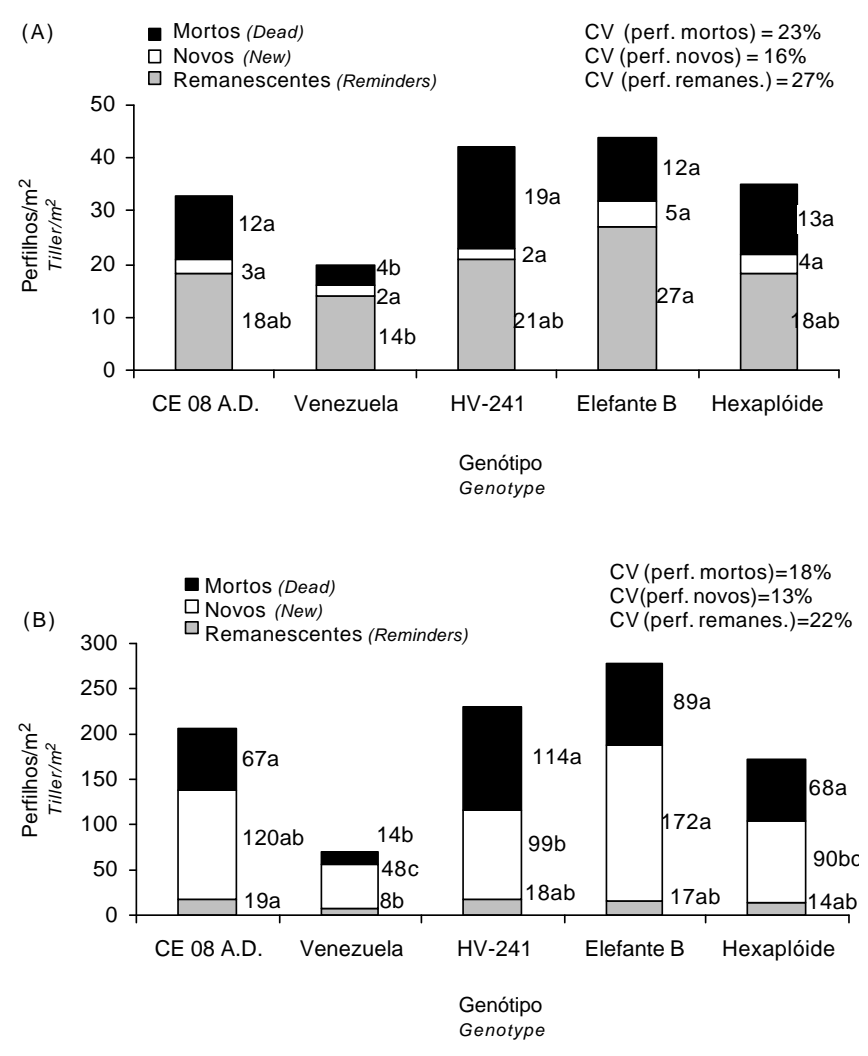

Figura 6 - Densidade das classes de perfilhos basais $(A)$ e aéreos (B) em genótipos de Pennisetum sp. no período pré-pastejo.

Figure 6 - $\quad$ Basal $(A)$ and aerial (B) pre-grazing tiller class density in Pennisetum sp. genotypes.

Médias seguidas de letras diferentes comparam as classes de perfilhos, entre os genótipos, e diferem $(P<0,05)$ pelo teste Tukey.

Means followed by different letters compare tiller class, among genotypes, and are different $(P<0.05)$ by Tukey test.

Os dados foram submetidos à transformação $\sqrt{x+1}$.

The data was transformed to $\sqrt{x+1}$.

A densidade de perfilhos basais remanescentes e aéreos remanescentes e novos diminuiu do primeiro para o segundo ciclo de pastejo $(\mathrm{P}=0,0073 ; 0,0033 ; 0,0748$, respectivamente). No entanto, a densidade de perfilhos basais novos e mortos, e aéreos mortos, não diferiu $(\mathrm{P}=0,3169$; 0,$5580 ; 0,3713$, respectivamente) entre os ciclos de pastejo (Figura 7).

Apesar de o pastejo estimular o perfilhamento (Olson \& Richards, 1988; Reece et al., 1999; Dong et al., 2004), as condições ambientais no período da seca não são favoráveis ao desenvolvimento de novos perfilhos (Laude et al., 1968), visto que a deficiência hídrica afeta a taxa de aparecimento de perfilhos (Morales et al., 1997).

A densidade de perfilhos aéreos e basais na pastagem é resultado da taxa de aparecimento e mortalidade dos perfilhos e da longevidade de cada perfilho (Pakiding \& 
(A)


Figura 7 - Densidade das classes de perfilhos basais (A) e aéreos (B) pré-pastejo em dois ciclos de pastejo.

Figure 7 - Basal (A) and aerial (B) tiller class density pre-grazing in two grazing cycles.

Médias seguidas de letras diferentes comparam as classes de perfilhos, dentro dos ciclos, e diferem $(P<0,05)$ pelo teste Tukey. Means followed by different letters compare tiller class, in cycles, and are different $(P<0.05)$ by Tukey test.

Os dados foram submetidos a transformação $\sqrt{x+1}$.

The data was transformed to $\sqrt{x+1}$.

Hirata, 1999). A diminuição dos perfilhos basais e aéreos remanescentes entre ciclos de pastejo pode estar relacionada à quebra destes perfilhos pelo pastejo ou à mortalidade, decorrente da remoção do meristema apical (Woodward, 1998), da longevidade do perfilho ou do efeito do déficit hídrico (Lauer \& Simmons, 1985).

É provável que as perdas de perfilhos basais e aéreos mortos nos genótipos de Pennisetum sp. tenham sido compensadas pela mortalidade dos perfilhos remanescentes, contribuindo para que a densidade de perfilhos basais e aéreos mortos não fosse alterada pelos ciclos de pastejo.

Não houve efeito significativo $(\mathrm{P}=0,7475)$ da interação genótipo $\times$ ciclo de pastejo sobre a densidade de perfilhos basais remanescentes $(19,5 \pm 1,3)$, novos $(3,1 \pm 0,1)$ e mortos $(11,7 \pm 1,0)(\mathrm{P}=0,7475 ; \mathrm{P}=0,2961$ e $\mathrm{P}=0,9817$, respectiva- mente) nem sobre a densidade de perfilhos aéreos remanescentes $(15,1 \pm 1,4)$, novos $(105,8 \pm 0,3)$ e mortos $(70,5 \pm 0,4)$ ( $\mathrm{P}=0,6800 ; \mathrm{P}=0,7260 \mathrm{e} \mathrm{P}=0,4177$, respectivamente).

A baixa densidade de perfilhos aéreos remanescentes, novos e mortos no Venezuela pode ter sido ocasionada pela alocação preferencial de reservas nos perfilhos basais. Sugiyama (1995) demonstrou que a produção de poucos perfilhos em genótipos de Festuca arundinacea Schreb foi resultado do maior acúmulo de reservas de carbono em detrimento à produção de muitos perfilhos.

Entre os demais genótipos, o CE 08 A.D. e Elefante B apresentaram maior densidade de lâmina foliar verde, menor porcentagem de material morto e maior densidade de perfilhos basais remanescentes e aéreos novos pré-pastejo; portanto, são genótipos com potencial para serem utilizados sob sistema de lotação rotacionada. Entretanto, a maior densidade de perfilhos aéreos novos no Elefante B sugere que maior quantidade desses perfilhos poderá escapar à desfolha. Desta forma, esse pode ser um dos fatores que ocasionaram maior densidade e porcentagem de lâmina foliar verde pós-pastejo neste genótipo (Figura 5 e 6).

A maior participação de material morto na biomassa aérea do HV-241 está associada à maior densidade de perfilhos basais e aéreos mortos. Como na maioria dos híbridos de capim-elefante com o milheto (Bogdan, 1977), o perfilhamento no HV-241 é intenso (Barreto et al., 2001), a alta mortalidade (relação perfilhos novos/perfilhos mortos menor que 1) pode ser resultado de um déficit no suprimento de carbono, promovido pela alta densidade de perfilhos aéreos e pelos efeitos do déficit hídrico no período de seca.

Embora o Hexaplóide, híbrido de capim-elefante com o milheto, cujo genoma foi duplicado, tenha aparentemente apresentado melhor desempenho que o HV-241, em comparação aos demais genótipos, foi inferior, apresentando baixa densidade de lâmina foliar verde e de perfilhos aéreos novos (relação perfilhos novos/perfilhos mortos aproximadamente igual a 1) e alta proporção de material morto prépastejo. Apesar de os híbridos de capim-elefante com milheto muitas vezes apresentarem superioridade em relação aos cultivares de capim-elefante (Sobrinho et al., 2005), a baixa persistência desses híbridos parece ser a principal limitação à produção animal (Macoon et al., 2002).

Os resultados comprovaram que há diferenças na estrutura e morfologia dos genótipos de Pennisetum sp. sob pastejo no período seco do ano. Essas diferenças podem afetar a persistência desses materiais na pastagem ao longo do tempo e o desempenho animal, principalmente em virtude da influência destas características sobre o consumo de MS sob pastejo. 
Os coeficientes de variação foram moderados ou elevados, o que pode ser explicado pelo caráter das avaliações realizadas, como no caso da estimativa da massa de lâmina foliar total, verde e seca, as quais foram obtidas por dupla amostragem. Além disso, a própria heterogeneidade da pastagem, característica de espécies de crescimento cespitoso e de porte alto, como o capim-elefante, também contribui para a obtenção desses valores. A diversidade da vegetação foi relatada por Cóser et al. (1989) como uma das causas de elevados coeficientes de variação.

Ressalta-se que, além dos aspectos estruturais e morfológicos da pastagem, o desempenho animal também pode ser afetado pela composição bromatológica e pela digestibilidade da forragem nesses genótipos. Estudos com maior período de avaliação devem ser realizados considerando a interação resposta dos genótipos ao pastejo $\times$ variações climáticas.

\section{Conclusões}

Os genótipos CE 08 A.D. e Elefante B destacaram-se pela maior densidade e participação de lâmina foliar verde na biomassa aérea e alta capacidade de perfilhamento.

No período seco do ano, o genótipo HV-241, híbrido de capim-elefante com milheto, é mais afetado pelos efeitos do estresse hídrico por apresentar alta participação de material morto em sua biomassa aérea.

\section{Literatura Citada}

BARRETO, G.P.; LIRA, M.A.; SANTOS, M.V.F. et al. Avaliação de clones de capim-elefante (Pennisetum purpureum Schum.) e de um híbrido com o milheto (Pennisetum glaucum (L.) R. Br.) submetidos a estresse hídrico. 1. Parâmetros morfológicos Revista Brasileira de Zootecnia, v.30, n.1, p.1-6, 2001

BAUMONT, R.; PRACHE, S.; MEURET, M. et al. How forage characteristics influence behaviour and intake in small ruminants: a review. Livestock Production Science, v.64, n. 1, p. 15-28, 2000

BLACK, J.L.; KENNEY, P.A. Factors affecting diet selection by sheep. 2. Height and density of pasture. Australian Journal of Agricultural Research, v.35, n.4, p.565 -578. 1984.

BOGDAN, A.V. The grasses. In: BOGDAN, A.V. (Ed.) Tropical pasture and fodder plants (grasses and legumes). London: Longman, 1977. 301p.

BULLOCK, J.M.; FRANKLIN, J.; STEVENSON, M.J. et al. A plant trait analysis of responses to grazing in a long-term experiment. Journal of Applied Ecology, v.38, n.2, p.253-267, 2001.

BURNS, J.C.; FISHER, D.S.; POND, K.R.J. Diet characteristics, digesta kinetics and dry matter intake of steers grazing eastern gamagrass. Journal of Animal Science, v.40, n.4, p.1251$1261,1992$.

BURNS, J.C.; SOLLENBERGER, L.E. Grazing behavior of ruminants and daily performance from warm-season grasses. Crop Science, v.42, n.3, p.873-881, 2002.

CHERNEY, D.J.; MERTENS, D.R.; MOORE, J.E. Intake and digestibility by wethers as influenced by forage morphology at three levels of forage offering. Journal of Animal Science, v.68, n.12, p.4387-4399, 1990.

CÓSER, A.C.; MARTINS, C.E.; CARDOSO, F.P.N. Produção de leite em pastagem de capim-elefante submetida a duas alturas de resíduo pós-pastejo. Ciência e Agrotecnologia, v.25, n.2, p.417-423, 2001.

CÓSER, A.C.; NASCIMENTO JR., D.; MARTINS, C.E. et al. Relação cobertura:peso em pastagens do planalto de Viçosa, MG. Revista Brasileira de Zootecnia, v.18, n.1, p.48-53, 1989.

DONG, S.K.; KANG, M.Y.; HU, Z.Z. et al. Performance of cultivated perennial grass mixtures under different grazing intensities in the alpine region of the Qinghai-Tibetan. Grass and Forage Science, v.59, n.3, p.298-306, 2004.

ENCARNAÇÃO, C.R.F. Observações meteorológicas e tipos climáticos das unidades e campos experimentais da Empresa IPA. Recife: Empresa Pernambucana de Pesquisa Agropecuária, 1980. 110p.

FAGUNDES, J.L.; SILVA, S.C.; PEDREIRA, C.G.S. et al. Índice de área foliar, coeficiente de extinção luminosa e acúmulo de forragem em pastagens de Cynodon sp. sob lotação contínua. Pesquisa Agropecuária Brasileira, v.36, n.1, p.187-195, 2001.

FREITAS, E.V.; LIRA, M.A.; DUBEUX JR., J.C.B. et al Características produtivas e qualitativas de clones de capimelefante (Pennisetum purpureum Schum.) avaliados sob pastejo na Zona da Mata de Pernambuco. Acta Scientiarum, v.26, n.2, p.251-257, 2004

GOMIDE, J.A.; WENDLING, I.J.; BRAS, S.P. et al. Consumo e produção de leite de vacas mestiças em pastagem de Brachiaria decumbens manejada sob duas ofertas diárias de forragem. Revista Brasileira de Zootecnia, v.30, n.4, p.1194-1199, 2001.

HODGSON, J.; CLARK, D.A.; MITCHELL, R.J. Foraging behavior in grazing animals and its impact on plant comunities. In: FAHEY, G.C. (Ed). Forage quality, evaluation and utilization. Lincoln: American Society of Agronomy. National Conference on Forage Quality 1994. p.796-827.

LAUDE, H.M.; RIVEROS, G.; MURPHY, A.H. Tillering at the reproductive stage in hardinggrass. Journal of Range Management, v.21, n.3, p.148-150, 1968.

LAUER, J.G.; SIMMONS, S.R. Photoassimilate partitioning of main shoot leaves in field-grown spring barley. Crop Science, v.25, n.5, p.279-282, 1985 .

LOPES, R.S.; FONSECA, D.M.; OLIVEIRA, R.A. et al. Efeito da irrigação e adubação na disponibilidade e composição bromatológica da massa seca de lâminas foliares de capimelefante. Revista Brasileira de Zootecnia, v.34, n.1, p.2029, 2005

MACOON, B.; SOLLENBERGER, L.E.; MOORE, J.E. Defoliation effects on persistence and productivity of four Pennisetum sp. genotypes. Agronomy Journal, v.94, n.3, p.541-548, 2002.

MELlO, A.C.L.; LIRA, M.A.; DUBEUX JR., J.C.B. et al. Caracterização e seleção de clones de capim-elefante (Pennisetum purpureum Schum.) na Zona da Mata de Pernambuco. Revista Brasileira de Zootecnia, v.31, n.1, p.30-42, 2002.

MORALES, A.S.; NABINGER, C.; MARASCHIN, G.E. et al. Efeito da disponibilidade hídrica sobre a morfogênese e repartição de assimilados em L. corniculatus L. cv. São Gabriel. In: REUNIÃO ANUAL DA SOCIEDADE BASILEIRA DE ZOOTECNIA, 34., 1997, Juiz de Fora. Anais... Juiz de Fora: Sociedade Basileira de Zootecnia, 1997. p.124-126

NEWMAN, Y.C.; SOLLENBERGER, L.E.; CHAMBLISS, C.G. Canopy characteristics of continuously stocked limpograss swards grazed to different heights. Agronomy Journal, v.95 n.5, p.1246-1252, 2003.

OLSON, B.E.; RICHARDS, J.H. Tussock regrowth after grazing: Intercalary meristem and axillary bud activity of tillers of Agropyron desertorum. Oikos, v.51, n.3, p.374-382, 1988. 
PAKIDING, W.; HIRATA, M. Tillering in a bahia grass (Paspalum notatum) pasture under cattle grazing: results from the first two years. Tropical Grasslands, v.33, n.3, p.171-176, 1999.

QUADROS, D.G.; RODRIGUES, L.R.A.; FAVORETTO, V. et al. Componentes da produção de forragem em pastagens dos capins Tanzânia e Mombaça adubadas com quatro doses de NPK. Revista Brasileira de Zootecnia, v.31, n.3 supl., p.13331342, 2002.

REECE, P.E.; BODE, R.P.; WALLER, S.S. Vigor of needleandthread and blue grama after short duration grazing. Journal of Range Management, v.41, n.4, p.287-291, 1999.

STATISTICAL ANALYSIS SYSTEM - SAS. SAS/STAT User's guide. Version 8. Cary: 1999. 1464p.

SOBRINHO, F.S.; PEREIRA, A.V.; LEDO, F.J.S. Avaliação agronômica de híbridos interespecíficos entre capim-elefante e milheto. Pesquisa Agropecuária Brasileira, v.40, n.9, p.873-880, 2005.

STOBBS, T.H. The effect of plant structure on the intake of tropical pasture. II- Differences in sward structure, nutritive value and bite size of animals grazing Setaria anceps and Chloris gayana at various stages of growth. Australian Journal of Agriculture Research, v.24, p.821-829, 1973.
SUPERINTENDENCIA DE DESENVOLVIMENTO DO NORDESTE - SUDENE. Dados pluviométricos mensais do Nordeste - Estado de Pernambuco. Recife, 1990. p.7879 (Pluviometria, 6).

SUGIYAMA, S. The relationship between growth and development of vegetative shoots in genotypes of tall fescue (Festuca arundinacea Schreb.). Annals of Botany, v.76, n.6, p.553$558,1995$.

WILM, H.G.; COSTELLO, O.F.; KLIPPLE, G.E. Estimating forage yield by the double sampling method. Journal of American Society of Agronomy, v.36, n.1, p.194-203, 1944.

WOODWARD, S.J.R. Quantifying different causes of leaf and tiller death in grazed perennial ryegrass swards. New Zealand Journal of Agricultural Research, v.41, n.2, p149-159, 1998. 